\title{
Effectiveness of Intraoperative Pulmonary Wedge Resection of Tumor Site Before Lobectomy for Early Lung Adenocarcinoma
}

\author{
MOTOAKI YASUKAWA, NORIYOSHI SAWABATA, TAKESHI KAWAGUCHI and SHIGEKI TANIGUCHI
}

Department of Thoracic and Cardiovascular Surgery, Nara Medical University School of Medicine, Nara, Japan

\begin{abstract}
Background/Aim: Circulating tumor cells (CTCs) are tumor cells shed from tumor sites and circulate in the peripheral blood. CTCs can be a surrogate biomarker of recurrence and prognosis. Because surgical manipulation could promote CTCs, it is important to reduce CTCs during surgery. This study aimed to evaluate the effectiveness of intraoperative wedge resection of the tumor site before lobectomy. Patients and Methods: A total of 297 resected stage I lung adenocarcinoma patients were retrospectively reviewed. Patients were divided into two groups: Wedge and Non-Wedge. Recurrence-free survival (RFS) curves were plotted using the Kaplan-Meier method. Cox regression analyses were used to evaluate the hazard ratio $(H R)$ with the endpoint RFS. Results: The 5-year RFS rates were $92.9 \%$ and $85.5 \%$, in Wedge and Non-Wedge groups, respectively $(p=0.006)$. Wedge resection was an independent factor associated with RFS (HR=0.342, 95\%CI=0.141-0.830, $p=0.018$ ). Conclusion: Wedge resection before lobectomy for lung adenocarcinoma patients can improve RFS rates.
\end{abstract}

Surgery is the most preferred treatment for non-small cell lung cancer (NSCLC) patients. Among early stage NSCLC patients, the 5-year overall survival rates range between 66 and $82 \%$ (1). In general, the most significant predictor of recurrence and prognosis in patients with NSCLC is cancer stage using the TNM classification, which also guides treatment decisions (1, 2). Nevertheless, each stage remains a heterogeneous group comprising tumors with different responses to treatment and overall outcomes. Previous studies have identified other histological parameters that have been correlated with an unfavorable prognosis, such as high histological grade, visceral pleural invasion, and lymphovascular invasion (3-5).

This article is freely accessible online.

Correspondence to: Motoaki Yasukawa, Department of Thoracic and Cardiovascular Surgery, Nara Medical University School of Medicine, Kashihara, Nara 634-8522, Japan. Tel: +81 744223051, Fax: +81 744248040, e-mail: myasukawa@naramed-u.ac.jp

Key Words: Lung adenocarcinoma, circulating tumor cell, prognosis.
Recently, some studies have demonstrated that circulating tumor cells (CTCs) in peripheral blood can be a surrogate biomarker of prospective recurrence and prognosis $(6,7)$. CTCs are released from the primary tumor into the bloodstream and have the potential to spread to distant sites and develop into micrometastatic deposits (8). Furthermore, surgical manipulation could promote the dissemination of tumor cells from a solid cancer into the circulation (9-11). Tumor cells can be detected in effluent venous blood during surgery (12). In addition, vascular invasion within the tumor is also common in lung cancer, which might be responsible for the high incidence of hematogenous spread of tumor cells (13). Among stage I NSCLC patients, the presence of lymphovascular invasion in pathology specimens varies from $5 \%$ to $40 \%$ (14). Though it is controversial whether the pulmonary vein (PV) should be ligated first, Wei et al. (15) have demonstrated that the PV-first group had significantly better outcome than the pulmonary artery (PA)-first group in terms of 5-year survival, recurrencefree survival, and lung cancer-specific survival. Furthermore, they have demonstrated that the PA-first procedure was an independent risk factor for the increment of CTCs during lobectomy for NSCLC in multivariate analysis.

As mentioned above, the PV-first procedure might be useful for prevention of the increment of CTCs due to surgical intervention. However, it is not possible for the PV to be ligated without the following surgical manipulations: dissection of the tissue around the PV and away from the lung. This procedure can squeeze tumor cells from the tumor site into the bloodstream. However, intraoperative pulmonary wedge resection of the tumor site before lobectomy might be superior in reduction of CTCs to the PV-first ligation method during lobectomy for NSCLC. The advantage of wedge resection of the tumor site before lobectomy is that the absence of the tumor could prevent release of tumor cells that may occur during lobectomy for lung cancer.

The aim of this study was to evaluate the effectiveness of intraoperative wedge resection of the tumor site before lobectomy. This is the first study to investigate the effectiveness of intraoperative wedge resection during lobectomy for stage I lung adenocarcinoma with a pathological tumor invasion size of 3-cm or less. 


\section{Patients and Methods}

Among 891 consecutive patients who underwent resection of NSCLC at Nara Medical University Hospital between January 2010 and December 2016, 297 pathological stage I lung adenocarcinoma patients, with a less than $3-\mathrm{cm}$ tumor infiltration diameter, who underwent complete resection (lobectomy) were selected and their medical records reviewed. The clinical $\mathrm{T}$ descriptor was reclassified based on the eighth edition TNM staging (2). Exclusion criteria for entry into the study were the presence of other concomitant malignant diseases and determination of NSCLC by intraoperative needle lung biopsy. The 297 patients were divided into two groups: the group of patients who underwent wedge resection of the tumor site before lobectomy (Wedge group, $n=166$ ) and the group of patients who did not undergo wedge resection of the tumor site before lobectomy (Non-Wedge group, $\mathrm{n}=131$ ).

We used the 3-port video-assisted thoracoscopic surgery (VATS) technique to resect the lung cancers. Wedge resection was performed using ring-shaped forceps. Once the ring-shaped forceps were locked, it was never released until completion of the wedge resection. The patients whose preoperative diagnosis was not yet decided, underwent wedge resection when the location of the tumor could be partially resected without any difficulties. During this period, we were not committed to PV-first ligation during lobectomy. Instead, we prioritized the ease of the lobectomy procedure regarding vessel ligation.

Follow-up examinations were symptom-oriented, but all patients received medical checkups and chest X-rays at least twice a year and whole-body computed tomography (CT) scans were performed at least once a year. The observation period began on the day of operation and terminated on December 31, 2018.

Either the chi squared test or Fisher's exact test was used, as appropriate, to analyze any correlation between the two groups. Overall survival curves and recurrence-free survival curves were plotted using the Kaplan-Meier method, and the statistical significance of differences between groups was determined by the log-rank test. Univariate and multivariate Cox regression analyses were used to evaluate the hazard ratio with the endpoint of overall survival (period from the day of operation to the day of death) or recurrence-free survival. All $p$-values were two-sided, and $p$-values of 0.05 were considered to indicate a statistically significant difference. All analyses were conducted using EZR on $\mathrm{R}$ commander version 1.33 (Saitama, Japan) (16).

This retrospective study was approved by our institute Ethics Review Board (No. 2263). The Ethics Review Board of our institute waived the requirement to obtain written informed consent from patients and approved the study protocol, because individual patients were not identified in this retrospective study.

\section{Results}

One hundred sixty-six patients in the Wedge group and 131 patients in the Non-Wedge group were included in this study. The median follow-up period was 50 months (range $=1-102$ months). Table I shows the clinicopathological characteristics of the patients in both groups. There were statistically significant differences in $\mathrm{pT}$ stage, the peripheral location of the tumor, and pleural invasion, which were more frequently
Table I. Patient clinico pathological characteristics.

\begin{tabular}{|c|c|c|c|}
\hline & $\begin{array}{l}\text { Wedge } \\
(\mathrm{n}=166)\end{array}$ & $\begin{array}{l}\text { Non-Wedge } \\
(\mathrm{n}=131)\end{array}$ & $p$-Value \\
\hline Age $<70 / \geq 70$ & $95 / 71$ & $63 / 68$ & 0.129 \\
\hline \multicolumn{4}{|l|}{ Gender } \\
\hline Male/Female & $84 / 82$ & $68 / 60$ & 0.907 \\
\hline \multicolumn{4}{|l|}{ CT findings } \\
\hline Pure GGN/Others & $52 / 114$ & $39 / 92$ & 0.801 \\
\hline \multicolumn{4}{|l|}{ Location } \\
\hline Peripherial/Others & $161 / 5$ & $83 / 48$ & $<0.001 *$ \\
\hline \multicolumn{4}{|l|}{ p-Stage } \\
\hline $\mathrm{Tmin} / \mathrm{T} 1 \mathrm{a} / \mathrm{T} 1 \mathrm{~b} / \mathrm{T} 1 \mathrm{c} / \mathrm{T} 2 \mathrm{a}$ & $8 / 21 / 69 / 41 / 27$ & $5 / 8 / 57 / 51 / 10$ & $0.017 *$ \\
\hline Invasive size of the tumor $(\mathrm{cm})$ & $1.77 \pm 0.69$ & $1.98 \pm 0.64$ & \\
\hline$\leq 2 />2$ & $111 / 55$ & $73 / 58$ & 0.055 \\
\hline \multicolumn{4}{|l|}{ EGFR mutation } \\
\hline Yes/No/Unknown & $13 / 80 / 73$ & $25 / 79 / 27$ & 0.103 \\
\hline Histological grade & & & 0.639 \\
\hline 1 & 63 & 57 & \\
\hline 2 & 85 & 61 & \\
\hline 3 & 18 & 13 & \\
\hline $\mathrm{Pl}+/-$ & $27 / 139$ & $10 / 121$ & $0.033^{*}$ \\
\hline Ly +/- & $34 / 132$ & $36 / 95$ & 0.170 \\
\hline $\mathrm{V}+/-$ & $28 / 138$ & $30 / 101$ & 0.238 \\
\hline \multicolumn{4}{|l|}{ Preoperative CEA } \\
\hline$<5 />5 \mathrm{ng} / \mathrm{ml}$ & $141 / 25$ & $99 / 32$ & 0.053 \\
\hline \multicolumn{4}{|l|}{$\begin{array}{l}\text { Period of days from point } \\
\text { out to operation }\end{array}$} \\
\hline$<90 />90$ & $44 / 88$ & $46 / 80$ & 0.604 \\
\hline Death & 6 & 5 & 1.000 \\
\hline Recurrence & 7 & 23 & $<0.001^{*}$ \\
\hline
\end{tabular}

CT: Computed tomography; GGN: ground glass nodule; EGFR: epidermal growth factor receptor; Pl: pleural invasion; Ly: lymphatic invasion; V: vascular invasion; CEA: carcinoembryonic antigen.

observed in patients in the Wedge group than in the NonWedge group (Fisher's exact test).

During the observation period, NSCLC recurrence was identified in 7 patients in the Wedge group and 23 patients in the Non-Wedge group. Six patients in the Wedge group and 5 patients in the Non-Wedge group died during the observation period. The 5-year overall survival rates were 94.9\% (95\% CI=87.6-98.0) and 95.3\% (95\%CI=88.9-98.0), in the Wedge and the Non-Wedge groups, respectively $(p=0.647)$ (Figure 1). The 5-year recurrence-free survival rates were $92.9 \% \quad(95 \% \mathrm{CI}=84.4-96.8)$ and $85.5 \%$ (95\% CI $=76.8-91.1)$, in the Wedge and the Non-Wedge groups, respectively $(p=0.006)$ (Figure 2$)$.

In the analysis of relative risk with the endpoint of overall survival, pleural invasion ( $\mathrm{pl}$ ) factor (i.e. $\mathrm{pT} 2 \mathrm{a} / \mathrm{pT} 1$ or less), vascular invasion (v) factor, and lymphatic invasion (ly) factor were indicators of survival (Table II). In the analysis of relative risk with the endpoint of cancer recurrence, gender, wedge resection, pure ground glass nodule (GGN) in CT, histological grade, pathological tumor infiltration diameter, $\mathrm{pl}$ factor, $\mathrm{v}$ 


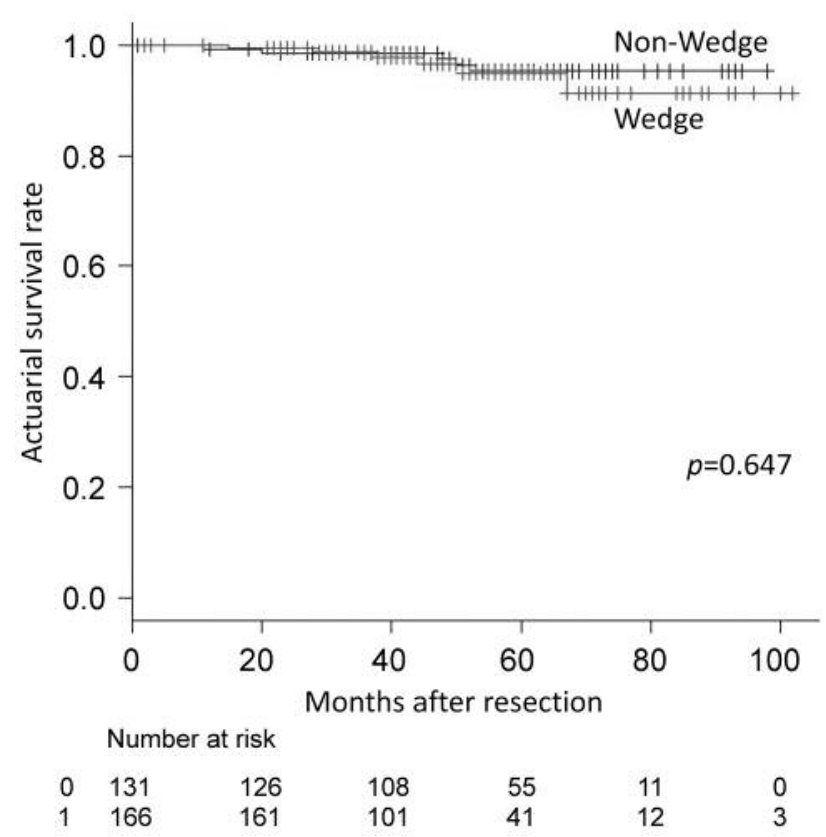

Figure 1. Overall survival curve for all patients according to receipt of wedge resection before lobectomy procedure. The 5-year overall survival rate was $94.9 \%$ in the Wedge group and $95.3 \%$ in the Non-Wedge group. The difference between the groups was significant $(p=0.647)$.

factor, and ly factor were indicators of recurrence as for survival, whereas in multivariate analysis, wedge resection and histological grade (Grade 2 or 3; non-lepidic adenocarcinoma) were independent recurrence predictors (Tables III and IV).

\section{Discussion}

In this study, the recurrence-free survival rate in the Wedge group was significantly better than that in the Non-Wedge group, and intraoperative wedge resection was shown to be one of the independent predictive factors of recurrence in 3$\mathrm{cm}$ or less stage I lung adenocarcinoma patients.

CTCs, originating from primary tumor sites, mobilize into the bloodstream as a result of intrinsic factors, such as active migration and invasion, or extrinsic factors, such as passive shedding by surgical manipulation, biopsy, and other iatrogenic sources (17). Previous studies have demonstrated that the presence of CTCs in peripheral blood can be a surrogate biomarker of prospective recurrence and prognosis $(6,7)$. CTCs are released from the primary tumor into the bloodstream and have the potential to spread to distant sites and develop into micrometastatic (18). Numerous studies have demonstrated that surgical manipulation could promote the dissemination of tumor cells into the circulation $(9-11,19)$.

It is important to prevent CTCs increment that may shed from the primary tumor due to surgical intervention for

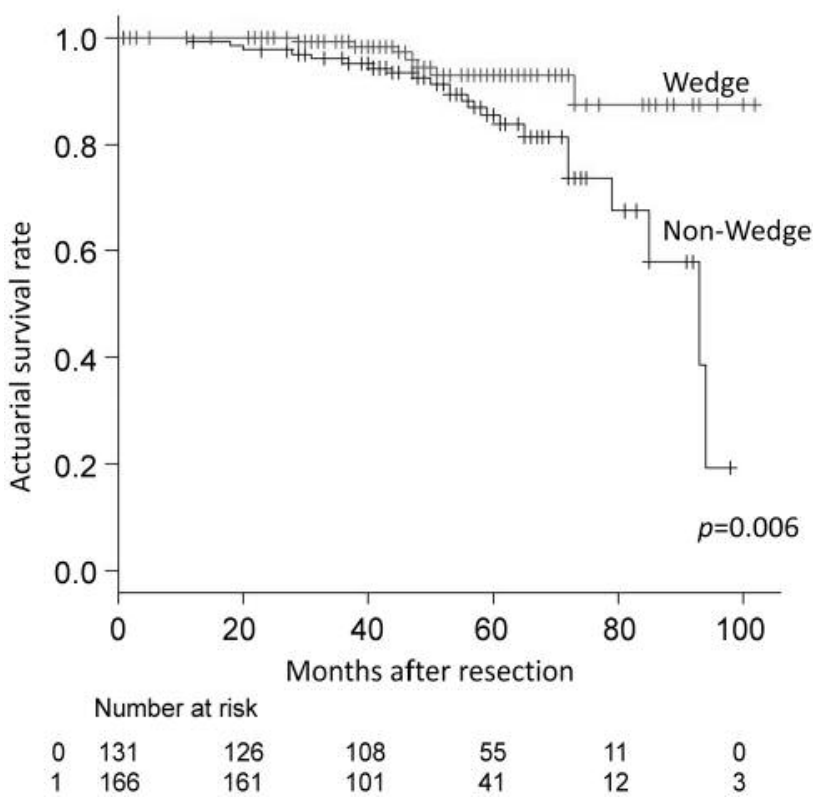

Figure 2. Recurrence-free survival curve for all patients according to receipt of wedge resection before lobectomy procedure. The 5-year recurrence-free survival rate was $92.9 \%$ in the Wedge group and $85.5 \%$ in the Non-Wedge group. The difference between the groups was significant $(p=0.006)$.

NSCLC. Interestingly, even for early stage lung cancer, CTCs can be detected in the rates of $60-80 \%(20,21)$. Duan et al. (17) have demonstrated that CTC counts after lobectomy for lung cancer were significantly higher than those before PV interruption. Their results suggest that surgical manipulation may potentially dislodge tumor cells into the PV, because the pulmonary vein is an overflow channel for tumor cell metastasis. Surgical manipulations of lung cancer may squeeze the tumor and further promote dissemination of tumor cells into the circulation (11).

There might be two methods that prevent the dissemination of tumor cells into the bloodstream due to surgical manipulations. First, a no-touch isolation technique. This surgical technique has been reported to reduce intraoperative shedding of tumor cells from a solid cancer into the circulation $(18,22-24)$. Another surgical technique involves ligating the effluent veins first, during surgery (25). As has been reported by McCulloch et al. (12), tumor cells can be detected in effluent venous blood during surgery. Furthermore, vascular invasion within the tumor is common in lung cancer, which may be responsible for the high incidence of hematogenous spread of tumor cells (13).

Although previous studies have demonstrated that intraoperative manipulation increases CTC shedding into the blood in patients with lung cancer, whether the drainage PV should be ligated first remains controversial (26). Hashimoto 
Table II. Univariate analysis of factors influencing survival of all patients after complete resection of primary lung cancer.

\begin{tabular}{|c|c|c|c|}
\hline & Hazard ratio & $95 \% \mathrm{CI}$ & $p$-Value \\
\hline Age $\geq 70$ & 2.209 & $0.646-7.553$ & 0.206 \\
\hline \multicolumn{4}{|l|}{ Gender } \\
\hline Male/Female & 1.703 & $0.499-5.819$ & 0.396 \\
\hline Wedge resection & 1.322 & $0.399-4.380$ & 0.648 \\
\hline CT findings: Pure GGN & $3.125 \times 10^{-9}$ & $0.000-$ Inf & 0.998 \\
\hline \multicolumn{4}{|l|}{ Location } \\
\hline Peripherial & 2.745 & $0.351-21.480$ & 0.336 \\
\hline \multicolumn{4}{|l|}{ Histological grade } \\
\hline Grade 2 or $3 /$ Grade 1 & 3.228 & $0.697-14.950$ & 0.134 \\
\hline $\begin{array}{l}\text { Invasive size of } \\
\text { the tumor }>2 \mathrm{~cm}\end{array}$ & 2.494 & $0.758-8.208$ & 0.133 \\
\hline EGFR mutation & 1.483 & $0.383-5.747$ & 0.569 \\
\hline $\mathrm{Pl}+($ i.e. $\mathrm{p}-\mathrm{T} 2 \mathrm{a} / \mathrm{T} 1$ or less $)$ & 4.158 & $1.213-14.250$ & $0.023 *$ \\
\hline $\mathrm{V}+$ & 7.815 & $2.287-26.700$ & $0.001^{*}$ \\
\hline $\mathrm{Ly}+$ & 4.944 & $1.444-16.930$ & $0.011^{*}$ \\
\hline Preoperative CEA $\geq 5 \mathrm{ng} / \mathrm{ml}$ & 1.572 & $0.417-5.928$ & 0.504 \\
\hline
\end{tabular}

CI: Confidence interval; CT: computed tomography; GGN: ground glass nodule; Inf: infimum; EGFR: epidermal growth factor receptor; Pl: pleural invasion; V: vascular invasion; Ly: lymphatic invasion; CEA: carcinoembryonic antigen.

Table III. Univariate analysis of factors influencing recurrence of all patients after complete resection of primary lung cancer.

\begin{tabular}{|c|c|c|c|}
\hline & Hazard ratio & $95 \% \mathrm{CI}$ & $p$-Value \\
\hline Age $\geq 70$ & 1.158 & $0.554-2.421$ & 0.696 \\
\hline \multicolumn{4}{|l|}{ Gender } \\
\hline Male/Female & 2.250 & $1.029-4.918$ & $0.042 *$ \\
\hline Wedge resection & 0.320 & $0.136-0.752$ & $0.009 *$ \\
\hline \multicolumn{4}{|l|}{ CT findings } \\
\hline Pure GGN & 0.260 & $0.079-0.858$ & $0.027 *$ \\
\hline \multicolumn{4}{|l|}{ Location } \\
\hline Peripherial & 1.042 & $0.446-2.437$ & 0.924 \\
\hline \multicolumn{4}{|l|}{ Histological grade } \\
\hline Grade 2 or $3 /$ Grade 1 & 5.052 & $1.761-14.490$ & $0.003 *$ \\
\hline $\begin{array}{l}\text { Invasive size of } \\
\text { the tumor }>2 \mathrm{~cm}\end{array}$ & 3.389 & $1.626-7.063$ & $0.001 *$ \\
\hline EGFR mutation & 1.591 & $0.717-3.528$ & 0.253 \\
\hline $\mathrm{Pl}+($ i.e. $\mathrm{p}-\mathrm{T} 2 \mathrm{a} / \mathrm{T} 1$ or less $)$ & 2.780 & $1.262-6.123$ & $0.011^{*}$ \\
\hline $\mathrm{V}+$ & 4.603 & $2.206-9.605$ & $<0.001 *$ \\
\hline $\mathrm{Ly}+$ & 3.377 & $1.636-6.972$ & $0.001 *$ \\
\hline Preoperative CEA $\geq 5 \mathrm{ng} / \mathrm{ml}$ & 1.619 & $0.738-3.553$ & 0.229 \\
\hline
\end{tabular}

CI: Confidence interval; CT: computed tomography; GGN: ground glass nodule; EGFR: epidermal growth factor receptor; Pl: pleural invasion; V: vascular invasion; Ly: lymphatic invasion; CEA: carcinoembryonic antigen.

et al. (11) have reported that the increased PV CTC count prior and subsequent to surgical manipulation for lobectomy was not significantly associated with the sequence of vessel interruption. Refaely et al. (27) have also demonstrated that
Table IV. Multivariate analysis of factors influencing recurrence of all patients after complete resection of primary lung cancer.

\begin{tabular}{lccc}
\hline & Hazard ratio & $95 \% \mathrm{CI}$ & $p$-Value \\
\hline $\begin{array}{l}\text { Wedge resection } \\
\begin{array}{l}\text { Histological grade } \\
\text { Grade } 2 \text { or 3/Grade 1 }\end{array}\end{array}$ & 0.342 & $0.141-0.830$ & $0.018^{*}$ \\
$\begin{array}{c}\text { Invasive size of } \\
\text { the tumor }>2 \mathrm{~cm}\end{array}$ & 1.867 & $1.578-13.850$ & $0.005^{*}$ \\
\hline
\end{tabular}

CI: Confidence interval.

the sequence of vessel interruption was not a risk factor for recurrence. He et al. (28) have reported that the sequence of pulmonary vessel ligation during VATS lobectomy for NSCLC has no different effects on overall survival and recurrence-free survival.

Recently, Wei et al. (15) have demonstrated that PV-first group had a significantly better outcome than PA-first group in terms of 5-year survival, disease-free survival, and lung cancer-specific survival. Furthermore, they have demonstrated that PA-first procedure was an independent risk factor for the increment of CTCs during surgery in multivariate analysis. Furthermore, Song et al. (29) have conducted a prospective randomized study regarding the invasiveness and adhesiveness of malignant tumor cells in PA and PV blood at the early and late periods during surgery, and suggested that ligation of the PV should be performed first during lobectomy for NSCLC. Surgical manipulation itself may stimulate the occurrence of blood micrometastases. Ligation of the PV-first during surgery may help prevent blood micro-metastases.

PV-first ligation should be good for the prognosis of surgically resected NSCLC patients. However, in the real world, the PV cannot be ligated immediately at the start of lobectomy before shedding of tumor cells occurs due to surgical manipulations such as dissection of the tissues and moving or turning over the lung. Before the PV is ligated from the lung during lobectomy, careful dissection of tissues around the PV and softly moving the lung could disturb the tumor site and squeeze the tumor cells out of the tumor and the tumor cells can then circulate throughout the bloodstream. Even bronchoscopic biopsy can increase the count of PV CTCs before the procedure $(17,30)$.

It has been assumed that CTCs released by surgical manipulation lead to metastasis, thus a no-touch isolation technique has been developed (19). During lung cancer surgery, one could hypothesize that CTCs could be dislodged by surgical manipulation; therefore, preventing the shedding of tumor cells would reduce the seeding of cancer cells, resulting in decreased metastatic implantation. 
We therefore hypothesized that the overall and recurrencefree survival is improved after wedge resection of the tumor site before lobectomy for early stage lung adenocarcinoma patients. The wedge resection technique could prevent surgical manipulation during lobectomy for NSCLC, and reduce the shedding and dissemination of tumor cells, similar to the notouch isolation technique. Our results show that wedge resection is effective in reducing recurrence of early stage lung adenocarcinoma. This effectiveness may be related to the reduction of CTCs that are related to surgical manipulation.

Ring-shaped forceps generate high pressure by compression, which can reduce the risk of tumor cell spreading. After wedge resection, the absence of the tumor could prevent release of tumor cells, therefore, wedge resection may be a surgical technique similar to no-touch isolation.

The wedge resection method is easy and can be performed immediately at beginning of the surgical procedure. Despite needing several cartridges of staples, the wedge resection method could result in improved oncological outcomes due to surgical manipulations.

The limitations of this study include its retrospective design and single-institution setting. Further investigation of the correlation between CTC detection and poor prognosis, and of wedge resection and CTC detection are required. A prospective study is needed to obtain more accurate evidence.

In conclusion, this is the first report to reveal the effectiveness of wedge resection before lobectomy for 3-cm or less stage I lung adenocarcinoma patients. The recurrence-free survival in the Wedge group was significantly better than that in the Non-Wedge group, and intraoperative wedge resection was shown to be one of the independent predictive factors of recurrence in $3-\mathrm{cm}$ or less stage I lung adenocarcinoma patients. Our data support the idea that wedge resection before lobectomy for lung cancer patients can be considered as a notouch isolation technique. This observation is helpful to improve the surgical intervention strategy and outcomes for patients with early stage lung adenocarcinoma.

\section{Conflicts of Interest}

The Authors declare that they have no conflicts of interest regarding this study.

\section{Authors' Contributions}

Study concept and design: M.Y.; Drafting of the manuscript: M.Y; Critical revision of the manuscript: N.S. and T.K.; Study supervision: S.T.

\section{References}

1 Goldstraw P, Chansky K, Crowley J, Rami-Porta R, Asamura $\mathrm{H}$, Eberhardt WE, Nicholson AG, Groome P, Mitchell A and Bolejack V; International Association for tha Study of Lung
Cancer Staging and Prognositic Factors Committee, Advisory Broads, and Participating Institutions; International Association for the Study of Lung Cancer Staging and Prognostic Factors Committee Advisory Boards and Participating Institutions: The IASLC Lung Cancer Staging Project: proposals for revision of the TNM stage grouping in the forthcoming (eight) edition of the TNM classification for lung cancer. J Thorac Oncol 11(1): 39-51, 2016. PMID: 26762738. DOI: $10.1016 /$ j.jtho.2015.09.009

2 Geisinger K, Rami-Porta R, Moreira AL, Travis WD and Nicholson AG: Lung cancer staging and grading. In: World Health Organization Classification of Tumors. Pathology and Genetics of the Lung, Pleura, Thymus and Heart. Travis WD, Brambilla E, Burke AP, Marx A and Nicholson AG (eds.). Lyon: IARC Press, pp. 14-15, 2015.

3 Borczuk AC: Prognostic considerations of the new World Health Organization classification of lung adenocarcinoma. Eur Respir Rev 25(142): 364-371, 2016. PMID: 27903658. DOI: 10.1183/16000617.0089-2016.

4 Jiang L, Liang W, Shen J, Chen X, Shi X, He J, Yang C and HeJ: The impact of visceral pleural invasion in node-negative non-small cell lung cancer: a systematic review and meta-analysis. Chest 148(4): 903-911, 2015. PMID: 25675151. DOI: 10.1378/chest.142765

5 Sung SY, Kwak YK, Lee SW, Jo IY, Park JK, Kim KS, Lee KY and Kim YS: Lymphovascular invasion increases the risk of nodal and distant recurrence in node-negative stage I-II. A nonsmall cell lung cancer. Oncology 95(3): 156-162, 2018. PMID: 29847825. DOI: $10.1159 / 000488859$

6 Cristofanilli M, Budd GT, Ellis MJ, Stopeck A, Matera J, Miller MC, Reuben JM, Doyle GV, Allard WJ, Terstappen LW and Hayes DF: Circulating tumor cells, disease progression, and survival in metastatic breast cancer. N Engl J Med 351(8): 781-791, 2004. PMID: 15317891. DOI: 10.1056/NEJMoa040766

7 Krebs MG, Sloane R, Priest L, Lancashire L, Hou JM, Greystoke A, Ward TH, Ferraldeschi R, Hughes A, Clack G, Ranson M, Dive C and Blackhall FH: Evaluation and prognostic significance of circulating tumor cells in patients with nonsmall-cell lung cancer. J Clin Oncol 29(12): 1556-1563, 2011. PMID: 21422424. DOI: 10.1200/JCO.2010.28.7045

8 Alix-Panabières $\mathrm{C}$ and Pantel $\mathrm{K}$ : Challenges in circulating tumour cell research. Nat Rev Cancer 14(9): 623-631, 2014. PMID: 25154812. DOI: $10.1038 / \mathrm{nrc} 3820$

9 Weitz J, Kienle P, Lacroix J, Willeke F, Benner A, Lehnert T, Herfarth $\mathrm{C}$ and von Knebel Doeberitz M: Dissemination of tumor cells in patients undergoing surgery for colorectal cancer. Clin Cancer Res 4(2): 343-348, 1998. PMID: 9516921.

10 Yamaguchi K, Takagi Y, Aoki S, Futamura M and Saji S: Significant detection of circulating cancer cells in the blood by reverse transcriptase-polymerase chain reaction during colorectal cancer resection. Ann Surg 232(1): 58-65, 2000. PMID: 10862196. DOI: 10.1097/00000658-200007000-00009

11 Hashimoto M, Tanaka F, Yoneda K, Takuwa T, Matsumoto S, Okumura Y, Kondo N, Tsubota N, Ysujimura T, Tabata C, Nakano $\mathrm{T}$ and Hasegawa $\mathrm{S}$ : Significant increase in circulating tumour cells in pulmonary venous blood during surgical manipulation in patients with primary lung cancer. Interact Cardiovasc Thorac Surg 18(6): 775-783, 2014. PMID: 24618055. DOI: 10.1093 /icvts/ivu048 
12 McCulloch P, Choy A and Martin L: Association between tumour angiogenesis and tumour cell shedding into effluent venous blood during breast cancer surgery. Lancet 346(8986): 1334-1335, 1995. PMID: 7475773. DOI: 10.1016/s01406736(95)92345-4

13 Bodendorf MO, Haas V, Laberke HG, Blumenstock G, Wex P and Graeter T: Prognostic value and therapeutic consequences of vascular invasion in non-small cell lung carcinoma. Lung Cancer 64(1): 71-78, 2009. PMID: 18790545. DOI: 10.1016/ j.lungcan.2008.07.011

14 Mollberg NM, Bennette C, Howell E, Backhus L, Devine B and Ferguson MK: Lymphovascular invasion as a prognostic indicator in stage I non-small cell lung cancer: a systematic review and meta-analysis. Ann Thorac Surg 97(3): 965-971, 2014. PMID: 24424014. DOI: 10.1016/J.athoracsur.2013.11.002

15 Wei S, Guo C, He J, Tan Q, Mei J, Yang Z, Liu C, Pu Q, Ma L, Yuan Y, Lin F, Zhu Y, Liao H, Wang W, Liu Z, Li Q, Jiang B, Li C, Xia L, Zhao K, Gan F, Cheng J, Wu Z, Wang Y, Lin Y, Kou Y, Che G, Chen L, Li J and Liu L: Effect of vein-first vs artery-first surgical technique on circulating tumor cells and survival in patients with non0small cell lung cancer. A randomized clinical trial and registry-based propensity score matching analysis. JAMA Surg 154(7): e190972, 2019. PMID: 31042283. DOI: $10.1001 /$ jamasurg.2019.0972

16 Kanda Y: Investigation of the freely available easy-to-use software 'EZR' for medical statistics. Bone Marrow Transplant 48(3): 452458, 2013. PMID: 23208313. DOI: 10.1038/bmt.2012.244

17 Duan X, Zhu Y, Cui Y, Yang Z, Zhou S, Han Y, Yu D, Xiao N, Cao X, Li Y, Liu S, Wang Z, Zhang W, Feng L, Zhang K, Shou J, Liu Z and Xu S: Circulationg tumor cells in the pulmonary vein increase significantly after lobectomy: A prospective observational study. Thoracic Cancer 10(2): 163-169, 2019. PMID: 30511800. DOI: 10.1111/1759-7714.12925

18 Sales JP, Wind P, Douard R, Cugnenc PH and Loric S: Blood dissemination of colonic epithelial cells during no-touch surgery for rectosigmoid cancer. Lancet 354(9176): 392, 1999. PMID: 10437871. DOI: $10.1016 /$ S0140-6736(99)92164-5

19 Matsutani N, Sawabata N, Yamaguchi M, Woo T, Kubo Y, Kawase A, Shiono S, Inuma H, Morita S and Kawamura M: Does lung cancer surgery cause circulating tumor cells? - A multicenter, prospective study. J Thorac Dis 9(8): 2419-2426, 2017. PMID: 28932547. DOI: 10.21037/jtd.2017.07.33

20 Li Y, Tian X, Gao L, Jiang X, Fu R, Zhang T, Ren T, Hu P, Wu Y, Zhao P and Yang D: Clinical significance of circulating tumor cells and tumor markers in the diagnosis of lung cancer. Cancer Med 8(8): 3782-3792, 2019. PMID: 31132233. DOI: $10.1002 /$ cam 4.2286

21 Chudasama D, Barr J, Beeson J, Beddow E, McGonigle N, Rice A, Nicolson and Anikin V: Detection of circulating tumour cells and survival of patients with non-small cell lung cancer. Anticancer Res 37(1): 169-173, 2017. PMID: 28011487. DOI: 10.21873/anticanres.11302
22 Turnbull RB Jr, Kyle K, Watson FR and Spratt J: Cancer of the colon: the influence of the no-touch isolation technic on survival rates. Ann Surg 166(3): 420-427, 1967. PMID: 6039601. DOI: 10.1097/00000658-196709000-00010

23 Liu CL, Fan ST, Cheung ST, Lo CM, Ng IO and Wong J: Anterior approach versus conventional approach right hepatic resection for large hepatocellular carcinoma: a prospective randomized controlled study. Ann Surg 244(2): 194-203, 2006. PMID: 16858181. DOI: 10.1097/01 sla.0000225095.18754.45

24 Gall TM, Jacob J, Frampton AE, Krell J, Kyriakides C, Castellano L, Stebbing J and Jiao LR: Reduced dissemination of circulating tumor cells with no-touch isolation surgical technique in patients with pancreatic cancer. JAMA Surg 149(5): 482-485, 2014. PMID: 24599353. DOI: 10.1001/jamasurg.2013.3643

25 Kurusu Y, Yamashita J, Hayashi N, Mita S, Fujino N and Ogawa M: The sequence of vessel ligation affects tumor release into the circulation. J Thorac Cardiovasc Surg 116(1): 107-113, 1998. PMID: 9671904. DOI: 10.1016/s0022-5223(98)70248-X

26 LV C, Zhao B, Wang L, Zhang P, Ma Y, Wang Y, Wu N, Wu Y and Yang Y: Detection of circulating tumor cells in pulmonary venous blood for resectable non-small cell lung cancer. Oncol Lett 15(1): 1103-1112, 2018. PMID: 29422972. DOI: 10.3892/ol.2017.7405

27 Refaely Y, Sadetzki S, Chetrit A, Simansky DA, Paley M, Modan B and Yellin A: The sequence of vessel interruption during lobectomy foe non-small cell lung cancer: Is it indeed important? J Thorac Cardiovasc Surg 125(6): 1313-1320, 2003. PMID: 12830050. DOI: 10.1016/s0022-5223(03)00022-9

$28 \mathrm{He} \mathrm{HH}$, He JX, Hao ZX, Wang W and He JX: Association between different sequences of vessel ligation during videoassisted thoracoscopic lobectomy and survival in patients with non-small cell lung cancer. J Thorac Dis 11(3): 686-693, 2019. PMID: 31019755. DOI: 10.21037/jtd .2019.02.69

29 Song PP, Zhang W, Zhang B, Liu Q and Du J: Effects of different sequences of pulmonary artery and vein ligations during pulmonary lobectomy on blood micrometastasis of nonsmall cell lung cancer. Oncol Lett 5(2): 463-468, 2013. PMID: 23420582. DOI: 10.3892/ol.2012.1022

30 Reddy RM, Murlidhar V, Zhao L, Grabauskiene S, Zhang Z, Ramnath N, Lin J, Chang AC, Carrott P, Lynch W, Orringer MB, Beer DG and Nagrath S: Pulmonary venous blood sampling significantly increases the yield of circulating tumor cells in early-stage lung cancer. J Thorac Cardiovasc Surg 151(3): 852858, 2016. PMID: 26614417. DOI: 10.1016/j.jtcvs.2015.09.126

Received November 13, 2019

Revised November 18, 2019

Accepted November 19, 2019 